\title{
Hypomagnesemia in critically ill cancer patients: a prospective study of predictive factors
}

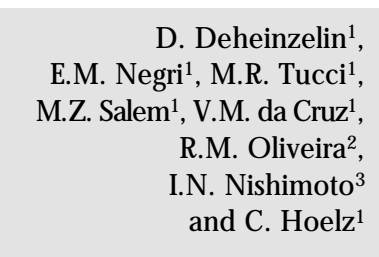

1 U nidade de Terapia Intensiva, Departamentos de

${ }^{2}$ Análises Clínicas e Hemoterapia and ${ }^{3}$ Epidemiologia e Bioestatística,

Centro de Tratamento e Pesquisa, Hospital do Câncer, São Paulo, SP, Brasil

\section{Correspondence}

D. Deheinzelin

Centro de Tratamento e Pesquisa

Hospital do Câncer

Rua Prof. Antonio Prudente, 211

9 andar, UTI

01509-010 São Paulo, SP

Brasil

Fax: + 55-11-3845-7457

E-mail: ddeheinz@uol.com.br

Publication supported by FAPESP.

$\ldots \ldots \ldots \ldots \ldots \ldots$

Received December 13, 1999 Accepted August 9, 2000

\section{Abstract}

Hypomagnesemia is the most common electrolyte disturbance seen upon admission to the intensive care unit (ICU). Reliable predictors of its occurrence are not described. The objective of this prospective study was to determine factors predictive of hypomagnesemia upon admission to the ICU. In a single tertiary cancer center, 226 patients with different diagnoses upon entering were studied. Hypomagnesemia was defined by serum levels $<1.5 \mathrm{mg} / \mathrm{dl}$. Demographic data, type of cancer, cause of admission, previous history of arrhythmia, cardiovascular disease, renal failure, drug administration (particularly diuretics, antiarrhythmics, chemotherapy and platinum compounds), previous nutrition intake and presence of hypovolemia were recorded for each patient. Blood was collected for determination of serum magnesium, potassium, sodium, calcium, phosphorus, blood urea nitrogen and creatinine levels. Upon admission, 103 (45.6\%) patients had hypomagnesemia and 123 (54.4\%) had normomagnesemia. A normal dietary habit prior to ICU admission was associated with normal $\mathrm{Mg}$ levels $(\mathrm{P}=0.007)$ and higher average levels of serum $\mathrm{Mg}$ $(\mathrm{P}=0.002)$. Postoperative patients $(\mathrm{N}=182)$ had lower levels of serum $\mathrm{Mg}(0.60 \pm 0.14 \mathrm{mmol} / \mathrm{l}$ compared with $0.66 \pm 0.17 \mathrm{mmol} / \mathrm{l}, \mathrm{P}$ $=0.006)$. A stepwise multiple linear regression disclosed that only normal dietary habits $(\mathrm{OR}=0.45 ; \mathrm{CI}=0.26-0.79)$ and the fact of being a postoperative patient $(\mathrm{OR}=2.42 ; \mathrm{CI}=1.17-4.98)$ were significantly correlated with serum $\mathrm{Mg}$ levels (overall model probability $=0.001$ ). These findings should be used to identify patients at risk for such disturbance, even in other critically ill populations.

\section{Introduction}

Hypomagnesemia is a common finding in current medical practice, mainly in critically ill and postoperative patients. Upon admission to the intensive care unit (ICU), the prevalence of this electrolyte disorder
Key words - Magnesium

- Magnesium deficiency

- Intensive care unit

- Electrolytes

- Surgery

- Dietary habits

- Postoperative patient ...................... 
morbidity of such patients. The etiology of magnesium deficiencies includes gastrointestinal and renal wasting, drug-induced loss, endocrine disorders, metabolic diseases, redistribution of magnesium stores and other conditions (5).

The causes of hypomagnesemia found upon admission to an ICU have not been previously studied. The objective of the present study was to investigate prospectively the incidence of hypomagnesemia in critically ill cancer patients and to determine predictive factors associated with such finding. Upon admission to the ICU, this population is expected to have electrolyte distur-

Table 1 - Population characteristics before admission and during permanence in the ICU.

\begin{tabular}{|c|c|c|}
\hline Variable & Category & Number \\
\hline \multirow[t]{2}{*}{ Age } & (<60 years) & 108 \\
\hline & (>60 years) & 118 \\
\hline \multirow[t]{2}{*}{ Gender } & Male & 126 \\
\hline & Female & 100 \\
\hline \multirow[t]{2}{*}{ Cause of admission } & Postoperative & 182 \\
\hline & Others & 44 \\
\hline \multirow[t]{2}{*}{ Orogastric cancer } & Present & 106 \\
\hline & Absent & 120 \\
\hline \multirow[t]{2}{*}{ Arrhythmia } & Present & 26 \\
\hline & Absent & 200 \\
\hline \multirow{2}{*}{$\begin{array}{l}\text { Cardiovascular } \\
\text { disease }\end{array}$} & Present & 80 \\
\hline & Absent & 146 \\
\hline \multirow[t]{2}{*}{ Renal failure } & Present & 19 \\
\hline & Absent & 207 \\
\hline \multirow[t]{2}{*}{ Chemotherapy } & Present & 51 \\
\hline & Absent & 175 \\
\hline \multirow[t]{2}{*}{ Platinum compounds } & Present & 20 \\
\hline & Absent & 206 \\
\hline \multirow[t]{2}{*}{ Diuretics } & Present & 24 \\
\hline & Absent & 202 \\
\hline \multirow[t]{2}{*}{ Antiarrhythmic drugs } & Present & 12 \\
\hline & Absent & 214 \\
\hline \multirow[t]{2}{*}{ Hypovolemia } & Present & 66 \\
\hline & Absent & 160 \\
\hline \multirow{2}{*}{$\begin{array}{l}\text { Arrhythmia during } \\
\text { ICU stay }\end{array}$} & Present & 28 \\
\hline & Absent & 198 \\
\hline
\end{tabular}

bances, not only because of the underlying disease, but also as a result of specific treatment regimens. The homogeneity of the population under study, admitted to the hospital with cancer as the primary cause, permitted analysis of the possible factors involved in this electrolyte disorder in these patients.

\section{Methods}

\section{Population}

A total of 226 consecutive patients admitted to the Critical Care Unit of the Hospital do Câncer A.C. Camargo, São Paulo, SP, Brazil, were studied. The patient population consisted of 126 males (56\%) and 100 females (44\%); 108 were under 60 years of age $(48 \%)$ and 118 were 60 years old or over $(52 \%)$. One hundred and eighty-two were postoperative patients $(80 \%)$ and 44 were medically treated patients $(20 \%)$. Population characteristics are detailed in Table 1. Most medical admissions were due to acute respiratory failure, acute renal failure, severe hypotension, sepsis, and cardiac arrhythmias. In all patients cancer was a primary active diagnosis.

\section{Study design}

The Committee for Human Studies of the Cancer Hospital approved the following protocol. Prior to admission to the ICU no patient had a record of hypomagnesemia. Upon entering the ICU, demographic data (age, gender), type of cancer, cause of admission, previous history of arrhythmia, cardiovascular disease or renal failure were recorded for each patient. Medications administered (particularly diuretics, antiarrhythmics, chemotherapy and previous use of platinum compounds) and types of nutritional support during the last $48 \mathrm{~h}$ before admission (normal habits, enteral support, parenteral support or fasting) were also recorded. On admission, special attention was paid to the presence of 
hypovolemia (defined by skin turgor, mucosal dryness, oliguria or low central venous pressure when recorded).

Upon admission to the ICU, a blood sample was collected for serum magnesium determination by a calorimetric method using chlorophosphanazo III (Cobas-Íntergra; Roche, Kaiser August, Switzerland). Potassium, sodium, calcium, phosphorus, blood urea nitrogen (BUN) and creatinine were also measured. Samples were run in duplicate.

When hypomagnesemia was found, magnesium sulfate was administered intravenously until normal levels were restored. After correction of magnesium levels, arrhythmia events were recorded until discharge from the ICU.

\section{Definitions}

In our laboratory, normal magnesium concentration is 0.62 to $1.03 \mathrm{mmol} / \mathrm{l}$, and hypomagnesemia is, therefore, defined as a serum magnesium level of $0.61 \mathrm{mmol} / 1$ or less; hypermagnesemia is defined as 1.04 $\mathrm{mmol} / \mathrm{l}$ or more.

\section{Statistical analysis}

One-way ANOVA was used for analysis of continuous variables. For categorical variables, serum magnesium levels were divided into low or normal levels and the chi-square test was used for comparison. Logistic regression was used to identify variables related to hypomagnesemia. The STATA 6.0 software package was used for statistical analysis and the level of significance was set at 0.05 .

\section{Results}

Upon admission to the ICU, 103 (45.6\%) of the 226 patients studied had hypomagnesemia and 123 (54.4\%) had normomagnesemia. Hypermagnesemia was not detected in any patient. Table 2 shows serum magnesium levels and the levels of other electrolytes obtained upon admission.

No correlation was found between magnesium concentration and age $(\mathrm{P}=0.16)$, sex $(\mathrm{P}=0.76)$, previous renal failure $(\mathrm{P}=0.47)$, cardiovascular disease $(\mathrm{P}=0.57)$, chemo-

Table 2 - Serum electrolyte levels obtained upon admission to the intensive care unit, defined as low, normal or high.

Absolute (percentage). Definitions: Magnesium, low $<0.61 \mathrm{mmol} /$; potassium, low $<3.5 \mathrm{mEq} / \mathrm{l}$; sodium, low $<135 \mathrm{mEq} /$; calcium, low total $\mathrm{Ca}<8.5 \mathrm{mg} / \mathrm{dl}$ or ionic $<1.12 \mathrm{mmol} / \mathrm{l}$; phosphorus, low $<2.5 \mathrm{mg} / \mathrm{dl}$; creatinine, low $<0.8 \mathrm{mg} / \mathrm{dl}$ and high $>1.5 \mathrm{mg} / \mathrm{dl}$; blood urea nitrogen (BUN), low $<7.8 \mathrm{mg} / \mathrm{dl}$ and high $>21.4 \mathrm{mg} / \mathrm{dl}$.

\begin{tabular}{lrrr}
\hline & Low & Normal & High \\
\hline Magnesium & $103(45.6 \%)$ & $123(54.4 \%)$ & \\
Potassium & $75(33.0 \%)$ & $151(67.0 \%)$ & \\
Sodium & $76(33.6 \%)$ & $149(66.4 \%)$ & \\
Calcium & $29(12.8 \%)$ & $196(87.2 \%)$ & \\
Phosphorus & $36(16.5 \%)$ & $187(83.5 \%)$ & \\
Creatinine & $122(53.8 \%)$ & $88(39.1 \%)$ & $16(7.1 \%)$ \\
BUN & 0 & $169(74.3 \%)$ & $57(25.7 \%)$
\end{tabular}

Table 3 - Univariate analysis comparing patients with low and normal serum magnesium levels according to the different clinical variables studied (chisquare test).

*Yes/no. BUN, Blood urea nitrogen.

\begin{tabular}{lccc}
\hline Variable & $\begin{array}{c}\text { Normal magnesium } \\
(123)\end{array}$ & $\begin{array}{c}\text { Low magnesium } \\
(103)\end{array}$ & $\mathrm{P}$ \\
\hline Sex (male/female) & $68 / 55$ & $59 / 44$ & 0.76 \\
Previous arrhythmia* & $17 / 106$ & $9 / 94$ & 0.23 \\
Previous cardiovascular & $44 / 79$ & $36 / 67$ & 0.89 \\
$\quad$ disease* & & & \\
Renal failure* & $10 / 113$ & $9 / 94$ & 0.87 \\
Previous chemotherapy* & $27 / 96$ & $24 / 79$ & 0.81 \\
Platinum compounds* & $11 / 112$ & $9 / 94$ & 0.96 \\
Diuretics* & $15 / 108$ & $9 / 94$ & 0.40 \\
Antiarrhythmics* & $8 / 115$ & $4 / 99$ & 0.38 \\
Hypovolemia* & $30 / 93$ & $37 / 66$ & 0.06 \\
Age $>60$ years* & $70 / 53$ & $49 / 54$ & 0.16 \\
K <3.5 mEq//* & $45 / 78$ & $29 / 74$ & 0.18 \\
Na <135 mEq//* & $44 / 79$ & $39 / 64$ & 0.75 \\
Total Ca <8.5 mg/dl & $35 / 88$ & $26 / 77$ & 0.56 \\
$\quad$ or ionic <1.12 mmol//* & & & \\
BUN >21.4 mg/dl* & $36 / 87$ & $22 / 81$ & 0.17 \\
Creatinine $>1.5$ mg/d/* & $7 / 116$ & $9 / 94$ & 0.37 \\
Postoperative patient* & $92 / 31$ & $90 / 13$ & 0.017 \\
Normal dietary habit* & $87 / 36$ & $55 / 48$ & $<0.01$ \\
& & &
\end{tabular}


therapy $(\mathrm{P}=0.80)$, use of platinum $(\mathrm{P}=$ $0.96)$, diuretics $(\mathrm{P}=0.40)$ or antiarrhythmics $(\mathrm{P}=0.38)$. The overall results are shown in Table 3.

There was no correlation between serum magnesium levels and serum potassium levels $\left(\mathrm{r}^{2}=0.06, \mathrm{P}=0.34\right)$ or serum sodium levels $\left(\mathrm{r}^{2}=-0.04, \mathrm{P}=0.53\right)$. A significant, but weak correlation was found between serum magnesium levels and calcium levels $\left(\mathrm{r}^{2}=0.295, \mathrm{P}=0.005\right)$, BUN levels $\left(\mathrm{r}^{2}=\right.$ $0.208, \mathrm{P}=0.0016)$ and creatinine levels $\left(\mathrm{r}^{2}=\right.$ $0.162, \mathrm{P}=0.01)$.

Serum magnesium levels varied according to previous nutritional support. A normal dietary intake prior to ICU admission was associated with normal magnesium levels ( $\mathrm{P}$ $=0.007)$ and the average levels of serum magnesium in this group were higher than those of patients receiving other forms of nutritional support $(P=0.002)$. Because of this correlation, we decided to investigate if cancer itself influenced this finding. After selecting cancer cases affecting the gastrointestinal tract and therefore impairing diet we found that, as expected, normal dietary intake was more frequent in patients with no orogastric cancer (only $48 \%$ of patients with orogastric cancer had a normal dietary intake compared to $78 \%$ of patients with other types of cancer; $\mathrm{P}<0.001$ ). However, orogastric cancer was not significantly more common in patients with low serum magnesium level $(\mathrm{P}=0.65)$, nor related to absolute values of serum magnesium.

Postoperative patients also had lower levels of serum magnesium $(0.60 \pm 0.14 \mathrm{mmol} /$ 1 vs $0.66 \pm 0.17 \mathrm{mmol} / \mathrm{l}, \mathrm{P}=0.006$ ).

After administration of $\mathrm{MgSO}_{4}$ in order to normalize the magnesium balance, the incidence of cardiac arrhythmias in the entire group was $12.39 \%$ ( 28 of 226 patients) and was correlated only with previous cardiovascular disease $(\mathrm{P}<0.001$, chi-square test). With regard to the incidence of arrhythmia, there was no difference between patients presenting with hypomagnesemia or with normomagnesemia.

A stepwise multiple linear regression disclosed that only normal dietary habit $(\mathrm{OR}=$ $0.45 ; \mathrm{CI}=0.26-0.79)$ and the fact of being a postoperative patient $(\mathrm{OR}=2.42 ; \mathrm{CI}=1.17$ 4.98) were significantly correlated with serum magnesium levels (overall model probability $=0.001)$.

\section{Discussion}

Magnesium is an essential element in many body functions. It plays a major role as a co-factor for adenosine triphosphatases and therefore is directly involved in important processes that require energy and also in protein synthesis mechanisms (6). In such a scenario, it is easy to predict the serious consequences brought about by magnesium deficiencies.

Magnesium is found in a large variety of foods, especially in green vegetables, nuts, grains, meat and seafood (6). In normal situations the kidney and the small intestine control magnesium excretion and its reabsorption, respectively, and serum levels are maintained within a normal range (5). Nevertheless, it is important to observe that serum levels of magnesium even remain normal in the presence of intracellular magnesium depletion and that low serum levels indicate severe magnesium deficiency (3).

Hypomagnesemia is a common finding in hospitalized patients (2) and it may basically be related to drug-induced gastrointestinal or renal losses (diuretics, aminoglycosides, etc.), pancreatitis, chronic diarrhea and inadequate intake (7). In this prospective study, we found that $46 \%$ of the patients admitted to an ICU in a tertiary cancer center presented hypomagnesemia. This finding agrees with previous reports showing a $61 \%$ incidence of hypomagnesemia in a postoperative ICU (1) or an incidence ranging from 20 to $45.7 \%$ in patients admitted to a medical ICU $(2-4,8)$.

Despite the significant morbidity related 
to hypomagnesemia for patients in a critical care setting, such as cardiac arrhythmias, respiratory muscle weakness and seizures (4), the most intriguing finding is that an imbalance of this electrolyte is significantly associated with increased mortality $(1,4)$. Therefore, understanding the causes of hypomagnesemia may be important to define and improve patient prognosis.

In our patients, logistic regression revealed that surgery and dietary regimen immediately before admission were the principal causes of hypomagnesemia. The lack of correlation observed in our study with previously described factors associated with hypomagnesemia such as use of diuretics, aminoglycosides or platinum compounds should be interpreted with caution. One possibility is that awareness of such side effect leads the physicians in charge to supplement magnesium when administering such drugs (9). Another possible explanation for our results is that, due to the relatively low number of patients with previous use of such drugs, a beta error occurred (10).

During surgery, magnesium loss has been ascribed to administration of magnesiumfree fluids and to serum catecholamine levels $(11,12)$. In fact, after hip surgery magnesium concentrations not only decreased significantly, but also led to worsening of cardiac arrhythmia (13).

Association of dietary habits with low serum magnesium levels has been described in ambulatory patients. Furthermore, low dietary magnesium was often associated with atherosclerosis, cardiovascular diseases, diabetes (14), wheezing and airway hyperreactivity (15). We did not record the dietary habits of our patients for a period over $48 \mathrm{~h}$ prior to admission. However, the significant correlation between different dietary regimens and low magnesium levels suggests that disturbances in the homeostasis of this electrolyte may occur very rapidly and that patients at risk should be closely monitored. Another explanation for this finding is that free access to a normal diet is only one indicator of better health conditions. However, there is no correlation between severity of illness scores and serum magnesium level, suggesting that in this case the dietary habit is not a simple marker of overall health conditions $(1,4)$.

We conclude that the incidence of hypomagnesemia in critically ill cancer patients is high. Basically, it is related to metabolic characteristics and not to any type of associated pathologies or previous treatment regimens. It is also directly related to the type of dietary intake, magnesium levels being best maintained with a free oral diet. Surgery is a major determinant of hypomagnesemia and such patients should be closely evaluated. The incidence of complications was similar for non-magnesium deficient patients and for those who continued to be deficient after magnesium replacement. Therefore, the above findings should be used to identify patients at risk for such deficiency.

\section{References}

1. Chernow B, Bamberger BSS, Stoiko $M$, Vadnais RNM, Mills RNS, Hoellerich $V \&$ Warshaw AL (1995). Hypomagnesemia in patients in postoperative intensive care. Chest, 2: 391-397.

2. Reinhart RA \& Desbiens NA (1985). Hypomagnesemia in patients entering the ICU. Critical Care Medicine, 13: 506-507.

3. Guérin $C$, Cousin $C$, Mignot $F$, Manchon M \& Fournier G (1996). Serum and erythrocyte magnesium in critically ill patients.
Intensive Care Medicine, 22: 724-727.

4. Rubeiz GJ , Thill-Baharozian M, Hardie D \& Carlson RW (1993). Association of hypomagnesemia and mortality in acutely ill medical patients. Critical Care Medicine, 21: 203-209.

5. Al-Ghamdi SMG, Cameron EC \& Sutton RAL (1994). Magnesium deficiency: pathophysiologic and clinical overview. American J ournal of Kidney Diseases, 24: 737-752.
6. McLean RM (1994). Magnesium and its therapeutic uses: a review. American J ournal of Medicine, 96: 63-76.

7. Arnold A, Tovey J , Mangat P, Penny W \& J acobs $S$ (1995). Magnesium deficiency in critically ill patients. Anaesthesia, 50: 203-205.

8. Ryzen E, Wagers PW, Singer FR \& Rude RK (1985). Magnesium deficiency in a medical ICU population. Critical Care Medicine, 13: 19-21. 
9. Shah GM \& Kirschenbaum MA (1991). Renal magnesium wasting associated with therapeutic agents. Mineral and Electrolyte Metabolism, 17: 58-64.

10. Altman DG (1997). Practical Statistics for Medical Students. Chapter 8: Principles of Statistical Analysis. Chapman \& Hall, London, UK, 152-178.

11. Hamill-Ruth RJ \& MacGory R (1996). Magnesium repletion and its effects on potassium homeostasis in critically ill adults: results of a double-blind, randomized, controlled trial. Critical Care Medicine, 24: 3845.
12. Kasaoka S, Tsuruta R, Nakashima K, Soejima Y, Miura T, Sadamitsu D, Tateishi A \& Maekawa T (1996). Effect of intravenous magnesium sulfate on cardiac arrhythmias in critically ill patients with low serum ionised magnesium. J apanese Circulation J ournal, 60: 871-875.

13. Zuccalà $G$, Pahor $M$, Lattanzio $F$, Vagnoni S, Rodolà F, De Sole P, Cittadini A, Cocchi A \& Bernabei R (1997). Detection of arrhythmogenic cellular magnesium depletion in hip surgery patients. British J ournal of Anaesthesia, 79: 776-781.

14. Ma J, Folsom AR, Melnick SL, Eckfeldt
J H, Sharrett AR, Nabulsi AA, Hutchinson RG \& Metcalf PA (1995). Associations of serum and dietary magnesium with cardiovascular disease, hypertension, diabetes, insulin, and carotid arterial wall thickness: the ARIC study. Atherosclerosis Risk in Communities Study. J ournal of Clinical Epidemiology, 48: 927-940.

15. Britton J, Pavord I, Richards K, Wisniewsky A, Knox A, Lewis S, Tattersfield A \& Weiss S (1994). Dietary magnesium, lung function, wheezing and airway hyperactivity in a random adult population sample. Lancet, 344: 357-362. 